\title{
anteproyecto de un bloque de viviendas entre medianerías en la calle de Espronceda, 19
}

\author{
MADRID - ESPAÑA, 1976
}

\author{
J. A. CODERCH GIMENEZ \\ G. CODERCH GIMENEZ \\ J. SANZ LUENGO
}

Arquitectos J. A. CODERCH Y DE SENTMENAT

$123-128$

\section{sinopsis}

Se trata de un edificio de planta rectangular constituido por dos sótanos para garaje, una planta baja de oficinas y locales comerciales y seis niveles de viviendas.

La planta tipo alberga doce viviendas de distintos tamaños, cuya principal característica es la de volcar todas las habitaciones principales al exterior, reservando los patios de ventilación sólo para las áreas de servicio y de comunicación vertical.

Para este concurso el estudio Coderch de Sentmenat vuelve a repetir su idea de volcar todas las habitaciones principales - dormitorios, sala de estar, comedor- al exterior, ventilando por los patios interiores únicamente el área de servicio - cocinas, lavaderos- y los núcleos de comunicaciones verticales situados en el eje central de la planta, consiguiendo con ello un desarrollo de gran compacidad y un máximo aprovechamiento de las superficies.

El edificio de planta rectangular consta de: dos sótanos - con el más bajo dedicado a garaje en su totalidad y el otro a garaje-, locales recreativos y vivienda del portero; una planta baja de locales comerciales y oficinas; y seis plantas de viviendas. Cada una de estas últimas plantas sitúa doce viviendas de distintas características y tamaños - con un mínimo de dos dormitorios y un máximo de cinco-, que reúnen, tanto por su tratamiento interior como por la funcionalidad de su distribución, los requisitos propios de una vivienda de calidad. 
Appel d'offres pour la construction d'un bloc d'habitations enrte mitoyennetés, rue Espronceda, 19, à Madrid - Espagne

José Antonio Coderch y de Sentmenat, architecte

J. A. et G. Coderch Giménez et J. Sanz Luengo, collaborateurs

II s'agit d'un immeuble au plan rectangulaire constitué par deux sous-sols pour gaet six niveaux destinés aux logemnets.

Le niveau type abrite douze logements de différentes dimensions, dont la caractéristes pièces principales donnant sur la rue, les pieces principales donnant sur la rue, ment pour les zones de service et de communication verticale.
Competition for an Apartment Building in the middle of the block on Espronceda Street, number 19, in Madrid -Spain

José Antonio Coderch y de Sentmenat, architect

J. A. and G. Coderch Giméneb and J. Sanz Luengo, collaborators

This is a rectangular-shaped building con sisting of two basements for parking, ground floor for offices and businesse premises and six floors of apartments.

The type floor plan houses twelve apartments of different sizes, having as their main characteristic that of situating their main rooms on the external facades, and reserving the ventilation patios for the service areas and vertical communication.
Ausschreibung eines Wohnungsblockes zwischen Trennmauern in der Strasse Espronceda, 19 . Madrid - Spanien

José Antonio Coderch y de Sentmenat, Architekt

J. A. und G. Coderch Giménez, und J. Sanz Luengo, Mitarbeiter

Es handelt sich um ein Gebäude rechteckigen Grundrisses, das aus zwei Kelleretagen für Parkplätze, einem Erdgeschoss für Büro. räume und Geschäftslokale und sechs Wohnungsetagen besteht.

Das Werkmal der Wohnungen verschiedener Abmessungen besteht darin, dass alle Wohnund Schlafräume nach aussen zeigen. Nur die Dienstzonen und Treppenverbindungen weisen Fenster zum Hof auf. 